\title{
"What Makes You Beautiful"--Analysis of Translation Strategies on Cosmetic Brands from Perspective of Marketing
}

\author{
Ning Li \\ School of Foreign Languages, Guangdong Pharmaceutical University, Guangzhou, PR China
}

Email Address:

Glorialeesmile@163.com

\section{To cite this article:}

Ning Li. "What Makes You Beautiful"--Analysis of Translation Strategies on Cosmetic Brands from Perspective of Marketing. International Journal of Applied Linguistics and Translation. Vol. 6, No. 3, 2020, pp. 68-74. doi: 10.11648/j.ijalt.20200603.12

Received: June 11, 2020; Accepted: July 2, 2020; Published: July 6, 2020

\begin{abstract}
As a result of the economic globalization, as meanwhile, the development of Chinese economy and the improvement of people's living standards, skincare products have become necessity. A large amount of skincare products from all over the world poured into our market, which is the communicative tool among different languages as well as the key to the market, instructions of skin-care products has become more crucial, thus much attention is also attached to their translations. A powerful brand identity of a cosmetic product is critical, because it can determine whether the product can survive the competition or be knocked out. Foreign skincare merchants have cudgeled their brains for earning money here. Obviously, translation of the brands should be a priority. The study attempts to explore the translation strategies of European and American cosmetic brands through case study, which aims to help cosmetic products achieve successful marketing in Chinese market. As meanwhile, the translation strategies also be discussed the cosmetic products' special efficacy and conclude principles of translating European and American cosmetic brands to realize successful marketing in China.
\end{abstract}

Keywords: Cosmetic Brands, Marketing, Translation Strategies

\section{Introduction}

As the economic globalization is gaining momentum, overseas skin care products especially that from western countries are occupying Chinese market. Through the ages, people have the same passion for beauty, and never stop pursuing beauty, though people's taste for beauty varies from different times. For the fact that hairdressing and makeup is not only connected with a person's appearance, but also has something to do with social economy, culture, value and custom, beauty is the eternal topic for human. No matter old or young, men or women, there is no difference in loving beauty. What's more, it is said that pursuing for beauty is the first step of the awakening of human ecological awareness. As we all know, cosmetology is derived from a Greek word which means beauty and creating beauty. Therefore, we can know that in ancient times, the scarce of materials never deterred their desires for becoming beautiful. According to historical records, they used fat, oil and natural perfume for simple skincare. For instance, in ancient China, women wore rough and cinnabar to add radiance. Chinese had paid less attention to cosmetic products compared with the attention paid to costumes and accessories. In spite of that, simple beauty products were made in ancient China. But now, skincare and cosmetic products are booming and providing customs a large range of choices, even cosmetics for men are selling well these days. Such progress is out of the shift of people's awareness and requirements that their appearance matters. Just as the saying goes, this is a society putting face as priority. Under the circumstance that competition in cosmetic industry is pretty severe, naming of one product is of vital importance. Besides that, product brand is closely related to the product's identity. In other words, a brand, which including additional value, represents an integration of all kinds of valuable information of the product, clearly identifying the product and creating a specific spirit for it which personalizes the product by endowing it with some characters. Therefore, a wildly accepted brand identity of a cosmetic product is critical. If a brand can connect with targeted consumers closely, the brand may obviously 
improve its information-conveying effect. If a product boosts good quality and is endowed with an attractive name, it surely will have enormous customers.

What is second to naming of brands is translation of brands in the global village. A successful brand translation can attract more customs as a result of its excellent effect of triggering consuming desire. Translation, closely related to intercultural communication, is the fundamental way to realize brand internationalization. Western brands are strange to Chinese, so an acceptable brand translation is the key to open cosmetic market in China. However, it's a complex work to translate western cosmetic brands into Chinese because of culture, language, tradition and awareness differences among different countries.

\section{Value of Cosmetic Brand}

\subsection{Importance of Naming Products}

Propaganda of a commodity is a vital way to win commercial competition. Under the circumstance of globalization, the publicity of a brand matters more in opening international market and cultivate the brand's reputation. As a result, brand translation becomes top priority for the producer. Chinese economy has been boosted as China pressing ahead with the policy of reform and opening up. Meanwhile, cosmetic industry is also thriving with a great deal of western cosmetic products pouring into Chinese market and Chinese cosmetic products going overseas. The integration of Chinese and western cosmetic products has been lifting the importance of cosmetic brand name translation. Brand, serving as a key media of introducing products into markets and occupying markets, is the bridge that connects producers and customers. Entrepreneurs utilize brand name to eradicate a well-regarded reputation, and customers depend on brands to get to know, purchase commodities. A qualified brand can take the responsibility of conveying the product's quality, reputation and publicity, and can meet consumers' psychological needs [1], thus leaving customer's deep impression and becoming a speechless shopping guide. As many foreign cosmetic products entering into China, the opportunities for Chinese cosmetic products merging into international market are on the rise. If one enterprise wants to win the competition and makes its product competitive, it must put emphasis on the translation of brands. Brand is the primary thing that is connected with the customers, so there is nothing more important than the brand. Improper brand translation can not only have difficulty of attracting customers, but also arouse customers' antipathy because of cultural conflicts. In such situation, the product's market performance is obvious. As a result, it's very important to delve more into the study of brand name translation which helps to make brand name translation cater to customers' psychological needs. Lonith, a socialist from University of Chicago, says in her book Communication that to achieve desired effect, information must succeed in attracting attention [2]. Brand, being as a critical part of a product, also has the feature. Different brands can cause different psychological reactions.

The importance of brand is gaining increasing importance. Some companies even take a policy of equalizing enterprise name and brands to improve propaganda effect. In an era of naming, four conditions of disseminating a product are naming, advertising, managing and technology. People put naming at a strategy height. The best marketing strategy is naming products. A good brand name is the guarantee of gaining long-term success. In the past, advertising was not common, brands played a minor role. But, at present, for all countries around the world, the importance of naming products surpasses technology. The reasons are as follows. First, product quality of highly industrialized countries is always reliable. Second, as the popularizing period cycle decreasing, life span of technology advantage is being shortened. Third, new products keep surging up. In present China, though technology is the foundation of surviving market, brand naming is catching more attention [3]. In a society where commodities are dazzling and in which the life pace is pretty fast, people's acknowledgement of products is becoming increasingly superficial. People tend to judge and speculate the essence of cases through their appearance. That means attractive outer packing contains excellent products, and beautiful names represent quality products. Such cognitive habits is extremely revealed in nowadays. Brand has been an effective marketing strategy for its role of the product's first impression to society. On the premise of good quality, a product which is properly named can become a favorite of consumers.

According to psychological researches, people react more swiftly to words that are familiar to people. As a result, producers should choose frequently used words as brands to make customers more familiar with their brands and products Besides that, cognition of words is related to word lengths that the longer a word is, the harder it can be recognized when words are similar in using frequency. So, if a brand wants to impress the customers quickly, being concise is an indispensable requirement for making brand name. For example, among one hundred globally famous brands, forty of them choose single-syllable words, twenty of them use disyllable, nineteen of them choose trisyllable, and seven brands use words that contain four or over four syllables. From this we can know that it is a tendency for brands to be precise and concise.

Language is endowed with social features, and brands are special languages which somehow show era features, ancient historical cultures and customs. For instance, numbers have different connotations for different countries. Chinese people are in favor of "six" and "eight" [4], because of harmonic tone, Chinese people take "six" as smooth, and "eight" as becoming rich. Chinese people avoid using "four" which sounds like "die" in Chinese. In America, people dislike "zero". Westerners avoid using "Friday" and "thirteen". Therefore, when translating brands, language annotation must be emphasized to avoid cultural taboo. 


\subsection{Importance of Cosmetic Brand Translation}

Since entering the new century, the competition in the cosmetics market has become increasingly fierce. On the one hand, worldwide cosmetics brands have launched global marketing in order to gain greater global market. On the other hand, China's cosmetics brand has been developing for many years and is taking its steps to enter global market. As a result, the trademark translation of cosmetics has become more and more frequent. In order to earn the recognition of consumers in other countries and regions, translation of brands must respect the culture of target market, obey the targeted market's language rules, and meet customers aesthetic requirements, in this way the product can become popular and win competition.

From the text function of the cosmetic brand, a brand should serve as a guidance to lead customers to purchase. The purpose of translation is to establish the brand image and stimulate consumers' desire to buy. The translation should be an advertisement translation and a purposeful translation. Different translation has different translating method, consequently different guiding principles. When it comes to the naming of imported goods, we must follow an important rule: respect for culture and cross geographical boundaries [5]. As a symbol of history and culture, language is also the carrier of custom, which is inseparable from social culture. Language is the symbol of culture, and culture is the carrier of language. British linguist Palmer deems that the language faithfully reflects the whole history and culture of a nation, reflects its various games and entertainment, beliefs and prejudices. Brand, serving as a unique linguistic phenomenon, is also a carrier of social cultural phenomenon, and is closely related to social history, national customs and other cultural factors. The product brand conveys the product information to the society while expressing subjective desire and rich cultural color. As a language phenomenon, the creation and dissemination of brand cannot ignore lore about culture. The brand and the receiver stand at the two ends of the transmission chain.

If a brand is only developed at home, it needs to consider its national culture, if it wants to go abroad, the brand must know well about the taboos of the target market. Only if we know the taboos and preferences of our nation and the foreign nations, can we know ourselves and the other side, so that the goods can be unimpeded when entering the foreign market. Consumers in different countries and regions have different opinions on the same brand due to different growth environment, customs, historical culture and values [6]. Materials that are blissful in our nation may mean something else. As a cultural transcendence process, brand translation is an important way to achieve cultural identity. The translator is the communicator of the culture. They mainly start from the readability of the original brand, in which the reader's acceptability cannot be ignored. Because the consumer is not the passive recipient, but a positive and energetic receiver who can proactively accept the quantity and quality information of the product from brand name.
The particularity of brand translation determines that its principles and strategies should not be loyal and smooth in the ordinary sense. This requires that the brand text itself is an attractive work of beauty. Translators shall make full use of various means to reproduce the connotation of the brand and the beauty of the language to the consumers, and expand the meaning of it when necessary to achieve the same publicity effect as the original text. After all, the essence of translation is a cross-cultural communication, translation is also an important factor to develop and enrich culture. After translation, the cosmetics brand should be given meaning as far as possible, at least it should appear meaningful. This kinds of brand name that have certain meanings, always give people some space of imagination and upgrade the brand, bringing better market performance and realize the original intention of trademark translation.

The meanings assigned to the translation of a brand can be descriptive, or it can be something that has a special meaning and is compelling. For example, "Guerlain", a distinguished French cosmetics brand, is called “嬌蘭” in Chinese. "Guerlain” is the name of its founder. “嬌” in Chinese means beautiful, delicate, and the Chinese character of “蘭” means dignity. Another example is "Olay”, translated as “玉蘭油” in Chinese, which embody the essence of the product. Characters in Chinese of “玉” and “蘭” are the two kinds of things that have good meanings in Chinese culture to show the circle and runniness of cosmetics, which can easily win the favor of female consumers. Such as "Johnsons" which is translated as “強生” with satisfaction of people's expectations that their baby can grow healthily by using the product.

\section{Characteristics of European and American Cosmetic Brands}

\subsection{Naming After Figure's Name}

Choosing this kind of brand naming method can promote the brand culture of its company very well, can also realize the mutual promotion between cosmetics brand and brand founder's name. France's noble cosmetics brand "Erno Laszlo" which was founded in 1927 by a Hungarian dermatologist, $D r$. Erno Laszlo; "Dior" is named after its funder Christian Dior; "HR (HELENA)" is named after Ms. Helena Rubinstein, the brand's founder. And other examples include "Ralph Laurence", "Stella Mcartney", "Givenchy", "Johns", "Chanel”, "Kiels'h", "SISLEY", "Mary Kay”, "L'Oreal”, "Mielon Lee” and "Cheng Mingming" are examples that are made up of surnames, occupations or nicknames.

Naming after place names, this method is usually naming after the city, town or originating place of raw materials. "Lancome", created by Armand Petitjean in 1935, is named after a castle in the middle of France. As the castle was surrounded by roses with romantic imagery, Armand himself thought that each woman was like a rose with her own features and gestures, so he named his brand after the castle. The rose also became the brand symbol of "Lancome" [7], 
which started from producing perfume, has become the all-around cosmetic brand that has been the guiding cosmetic trend. American brand Avon is named after Shakespear's hometown of stratefort-on-avon. French cosmetics brands "Vichy", "Biotherm", "Avene" and so on are named after some small towns famous for mineral water or hot spring water.

\subsection{Naming by Using Common Nouns}

Many western cosmetic brands use common nouns. Because of the personality liberation and the openness of thought in western countries, many merchants use the direct language to promote the beauty of cosmetics. "Aesop", Australian cosmetics founded in 1987, is named after Aesop's Fables. "Aesop" takes the lead in promoting organic ideas on the basis of natural plant skin care, and combines the philosophy of "Rational" life with internal and external conditioning. Other examples also include "Fresh", "Benefit", "Joy", "Impress", "Makeup Forever" and so on.

Moreover, the competition in the cosmetics market is very fierce today, many manufacturers are pursuing novelty. A unique product name is an important part of brand marketing. In order to avoid the similarities with other brands, many businesses will create new words as brands, for example, "DKNY", "Clinique", "YSL", "IPSA". Businesses also tend to add numbers to make brands unique, such as "H2O", "2N", "Bio2". This method of naming brands is usually applied by producers who want to make their brands novel and original.

\section{Methods of Translating on Cosmetic Brands}

\subsection{Transliteration}

Transliteration means to imitate the pronunciation of the original language and translate the original names into the target language. This method is simple and easy to use, which can not only maintain the original quality of the brand, but also reflect the aesthetic feeling of the original brand [8]. Several brands are based on people or place names. When a brand is named after a name, it is either using the reputation of a famous person, or coming from the impressive character of the fairy tale. Such as "JURLIQUE", the natural skin care brand was created in 1985, is the combination of names of chemist Jurgen Klein and his wife Ulrike Knew, which represents the power of the couple's union. The name "Maybelline" is made up of American chemist William's sister, Maybel, and the second half of Vaseline.

Transliteration can sometimes use the pronunciation of foreign languages to attract customers who would like to try fancy products [9]. Therefore, transliteration is the best choice for this type of brand. But the translator should pay more attention to the choice of the target language, and negative meaning should be avoided. Sometimes, it is difficult to find a target language corresponding to the original language when translating brands. Even if you can find one, it can mean something completely different, or has a negative cultural connotation, such as "Max Factor", which is translated as “蜜絲佛陀” in Chinese.

\subsection{Literal Translation}

The translation is faithfully translating the literal meaning of the original brands. This translation method preserves the literal meaning, emotion and culture of the original brands. Brands that have good meaning, health image or special symbolic meaning can be translated literally, such as the brand “Opium perfume” of “鴉片”, “Caleche” of “小馬車”, "Ivoire" of “象牙” and "Paris" of “巴黎” in Chinese marketing.

\subsection{Free Translation}

Free translation mainly refers to translation according to the meaning of the original text, which is applied mainly in the context of where there is great cultural difference between the original and the target language [10]. From the perspective of cross-cultural communication and cultural exchange, free translation can reflect the diversity of different language nationalities in ecological culture, language culture, religious culture, material culture and social culture. Targeted nation's language features can be well demonstrated by free translation.

Different countries have different cultural backgrounds. There are differences between eastern and western cultures. Each culture has its own unique social norms, religious beliefs and moral standards. If such factors in cross-cultural communication are ignored, the translation of brands will be ambiguous. The translation method includes pure translation and cultural translation, which are usually used in translation with obvious foreign words. The translation of the brand name mainly reflects that the original meaning of the translation after the translation is the same or similar to the original meaning of the foreign word [11]. This method can better restore the intention of the founder of the brand, and also benefit the integration of the original brand in another country. However, such translation method can only be used to translate words that means equally in two different language and cultural environments.

Cultural translation refers to the translation that although the original foreign words have their own meanings, literal translation can not convey the real intention of the original meanings. In order to combine the brand and brand culture well, we must process the original name. This way of brands translated is called as cultural translation. Take the brand of "Apollo" for an example, the brand name comes from the Greek Myths, is translated as “阿波羅” in Chinese. But it doesn't make any sense in China, in order to achieve the purpose of communication, merchants translated it as “太陽 神” in Chinese which has a positive connotation and more acceptable in China.

\subsection{Other Translation Strategies}

There is also combined translation which means combing 
translation and literal translation of brands. This method can not only combine the rhythmic beauty of the language, but also give consideration to the characteristics of the product or the purpose of the designer. For example, "Oil of Ulan" is translated as “玉蘭油”, this combination retains its original pronunciation and gives the brand name a positive Chinese connotation, which caters to the female aesthetic psychology. Most translation of brands can adopt rhetorical devices like pun, alliteration, clipping, homophony, personification, onomatopoeia and exaggeration to express the spirit, quality, characteristic and purpose of enterprise products directly by combining the similarities and similarities between Chinese and English cultural backgrounds [12]. As a result, customers can associate the products with its features. Using pun to translate brands can retain the original pronunciation of western brands and make the translation have similar connotations with original one, thus conveying the expectation of the product or enterprise. For example, French cosmetic brand “Biotherm" which is translated into “碧歐泉”. The translation conveys the meaning of moisturizing, pure and cleaning. And the main function of the product is moisturizing which is similar to the Chinese translation meaning.

Translation of brand name by using clipping, and homophony makes the translated brand name more succinct, unique, and easy to convey information. Using personification, onomatopoeia, and exaggeration to translate brands can make the brand name more vivid and attracting. For example, the lipstick whose brand name is "Kiss Me" and the translated version is “奇士美”. The translation is a clever and witty illustration of the feature of lipstick and hints of the strange beauty of the lipstick. "Pantene" suggests that the shampoo contains multiple vitamins and can make customers associated it with a beautiful brunette. Then the customers believe that using the product can make them have attractive hair and become as beautiful as the associated brunette. What's more, the "Whisper" has the meaning of being as soft as a whispering kiss, comfortable, tender and safe. It ensures customers that it's very safe and comfortable to use their product in the translation of “護舒寶”. The translation of “Crest” is “佳潔士” which makes customers associate the product with cleaning guard. People surely think the product has strong cleaning effect. “佳” in Chinese means positive, good and nice. Therefore, the translation creates a potent, active and energetic product image, stimulating shopping desire.

\section{Case Study on Cosmetic Brands}

\subsection{Consumers' Psychological Needs}

Consumer psychology is an important branch of psychological research. It studies the psychological phenomena and behavior patterns in consumer activities. This means that the study of consumers' thinking in choosing products and understanding consumer psychology is the premise of understanding consumer behavior. Therefore, for enterprises, taking full advantage of consumer psychology can increase consumption behavior and increase profits. For example, translating the soap brand name "Safeguard" as “舒 膚佳” follows the principle of catering to customers' psychological needs. “舒” in Chinese is a verb and means reliving, decompressing and solacing. “膚” in Chinese is skin, “佳” is an adjective which means good, beautiful and all the other positive meanings. The translation refers to that the soap can solace dis-comfortableness of skin, which is satisfied the customers' expectation of having a good using experience. Shampoo brand “Rejoice” is translated as “飄柔”, In Chinese it means “飄逸柔順”, in English it is smooth and soft. The translation makes customer believe that by using the shampoo, they can have smooth and shiny hair. The translation accurately tells the essence of its product of making its principle obvious to various customers for the need of the target readers.

To cultivate an attractive and competitive reputation, many business operators take pains to obtain a brand that is attractive and competitive. Brand name translation is a language art. Since there are many factors involved in the translation, while translating brands, translators should consider the differences between cultures, aesthetics, and fully utilize imagination and creativity. Brand is increasingly important in Chinese. National psychology can be the embodiment of national spirit, while folk culture is a popular culture closest to the public [13]. The effect of these two on brands is more direct and obvious than the national spirit. If we pay less attention to Chinese consumer' aesthetic psychology, consumption psychology and traditional habits, and ignore the colorful folk culture, we will not be able to obtain the most extensive "mass basis" for brand translation.

Since brand translation is the second naming of products, no matter how many principles and requirements of brand translation exists, the basic translating principle is that brands are related to the product attributes. The national spirit is deeply rooted in people's soul and has tenacious vitality, which is the highest guideline for people's thoughts and behaviors [14]. Therefore, in the process of foreign brand translation, we should try to make the translation of the brand based on our national spirit, so as to win the recognition and acceptance of the consumers.

\subsection{Consumers' Aesthetic Needs}

Brand is the title of product, which represents the visualization of products and enterprises. Therefore, a good brand name can attract people's attention, so that consumers will not forget it. For example, the translation of “Clean-Clear” is “可伶可俐” which has great rhyme and is catchy and easy to be remembered. In addition, different people have different aesthetic needs, and different kinds of products should be targeted at different consuming groups when conducting brand translation. Therefore, brand translation should target at different consumers.

For most of female products, such as cosmetics, skin care products, clothing and shoes, are often named after words with feminine colors. "Revlon” is translated as “露華濃” 
which is derived from great Chinese poet Li Bai's work. This poem is used to describe Yang Yuhuan, one of the four beautiful women in ancient China. When Chinese people see “露華濃”, they will think of the poem and the beauty of Yang Yuhuan, which will arouse their desire to buy the cosmetic product. Other examples can be included as “VIGHY” of “薇姿”, “Estee Lauder” of “雅詩蘭黛”, “Lancome” of “蘭蔻”. In order to have commercial value, the naming of brand should make aesthetic effect an important position which propagandizes the product and also bring customers sense of beauty.

\subsection{Necessity on Cultural Traditions of Target Market}

As a vital element of our national culture, brand plays a role which is called as commercial culture. The most important role of brand is distinguishing one merchandise from another, which means brand provides much information on various productions that consumers may decide whether to buy or not just by a simple look on its brand. However, it's a time called information-explosion period, which means there are so many information about language. As a special language, brand messaging has many distinctive features, and it also has some peculiar purpose [15]. Only concentrating on these features and differences can we translate these brands into Chinese accurately, which means Chinese can figure them out easily though the stuffs are from different country and impacted by different culture [16]. As we all know, the cultural difference between the east and the west has been existed for a long time, The social regulation, religious believe and moral standards are quite different. If merchants just neglect this cross-cultural communication, they will make mistakes in translating the brands into Chinese.

Imagine the following scenario for example, while a man creating a kind of perfume named "Opium", he wants to let others know his product is pretty attractive. If we just translate it into Chinese without thinking about the underlying meaning, people just can't get what merchants want to show, which means it finally turns out to be negative effects on the deal [17], just like opium will bring Opium War back to people's mind, the war caused a lot damage to Chinese nation. All merchandise's sense of belonging is to be carried to consumers' home. To do this, first step, the stuff should be accepted by consumers. When it comes to cosmetics, things are the same. Only the brand and the merchandise are accepted by consumers can we define them in a proper and popular way, while the merchandise will gain an excellent market performance.

\section{Conclusion}

In order to access to the Chinese market, alien merchants' most important task is to translate the brands correctly and reasonably, which means the name should be recognized and accepted by Chinese consumers. Because consumers only take notice of the brands at their first look, the brands become the only way people can imagine what the product looks like. Therefore, you can image how important the translation is. In order to improve marketing effectiveness, we should proceed with consumer psychology, market culture, aesthetics demand of language. In this way can target consumers accept what we revealing. In addition, translators should avoid linguistic taboos, which come from linguistic habits and folk culture. Cosmetics from Europe and the United States need an attractive Chinese brand, so that they can sells well in China. The translator must respect the culture of China and cater to the code of Chinese language, meet aesthetic psychological needs of consumers, and gain more consumers and sales for it.

Nowadays, it is very important to translate foreign brands appropriately and exactly. There are many aspects of the concept of brands translation, such as linguistics and intercultural communication. Brand translation not only achieves language equivalence in target language, but also let people pay more attention to the transmission of brand information and culture to the target language. Therefore, the translation of brand should not be arbitrary, cosmetic merchant who follows the corresponding translation principles may sell well in Chinese market. A good brand translation is so important for enterprises to executive their internationalization strategy. Appropriate translation can foster the healthy image of an enterprise, while endowing their products with vitality and attraction. In this way, consumers may realize the value of their brands, and then open their wallets to promote consumption. While translating brands, which functional characteristics should take the precedence for target aesthetic demanding. Use transliteration, be flexible, translation techniques, making the brands sound soothing, these matters need take into account while trans-national marketing is going on. Moreover, the study also probe into the foreign enterprise introduce their brands into Chinese market, it also provides the solution under the current globalization with the demonstration on various traditional Chinese brands into the world market.

\section{References}

[1] Doreen Kum, Yih Hwai Lee, Cheng Qiu. Testing to Prevent Bad Translation: Brand name Conversions in Chinese-English Contexts [J]. Journal of Business Research, 2010 (6): 21-33.

[2] Fade Wang. An Approach to the Translation of Brands [J]. Theory and Practice in Language Studies, 2012 (9): 34-47.

[3] Ford, Jonathan. Future Beauty [J]. Soap, Perfumery and Cosmetics, 2014 (3): 31 50.

[4] Gerard A. Athaide, Richard R. Klink. Creating Global Brands: The Use of Sound Symbolism [J]. Journal of Global Marketing, 2012 (4): 42-46.

[5] Kavin Lane, Keller. Strategic Brand Management [M]. Beijing: China Renmin University Press, 2016.

[6] Nida, Eugene. Language and Culture-Contexts in Translating [M]. Shanghai: Shanghai Foreign Language Education Press, 2001. 
[7] Qiang Kang. A Contrastive Study of Brands in English and Chinese [J]. Cross-Cultural Communication, 2013 (6): 42-56.

[8] Shuttleworth, Mark \& Cowie, Moira. Dictionary of Translation Studies [M]. Manchester: St. Jerome, 1997.

[9] Venuti, Lawrence. The Translation Studies Reader [M]. New York: Routledge, 2004.

[10] Chen Jinmei. Discussion on the Naming of Commodity [J]. Rhetoric Study, 1997 (3): 11-12.

[11] Du Shuling. On the Chinese Translation of Cosmetics Brand Names from Perspective of Functionalist Translation Theory [D]. Beijing Foreign Languages Studies, 2015.

[12] Pang Yanjie. Comparative Study on Diversity between English and Chinese Brands [J]. Journal of Yunnan University of Finance and Economics, 2011 (4): 156-158.
[13] Song Qiuyan. A. Brief Analysis of the Differences in Cultural values between Chinese and Western Cosmetics Advertisements [J]. Journal of Culture and Education, 2017 (16): 71-72.

[14] Yang Junxia, Yang Xiaorong. Analysis on Translation Strategies of Cosmetics Trademark Names [J]. China Commerce and Trade, 2010 (17): 228-229.

[15] Wang Yanxi. Book of Advertising English [M]. Beijing: University of International Business and Economics Press, 2004.

[16] Zhang Jing. Cultural Factors on Brand Naming of Import and Export Commodities [J]. Journal of Yulin College, 2013 (3): 106-109.

[17] Zhu Yajun. Research on Naming of Commodity [M]. Shanghai: Shanghai Foreign Language Education Press, 2003. 